\title{
Research on the possibilities of using linear observation models in welding processes
}

\author{
Al-Shamkhee Ameer Abdulkadhim Oudah ${ }^{1}$, Shepelev Anatoliy Fedorovich ${ }^{2}$, Finaev Valeriy Ivanovich ${ }^{1}$, \\ Zargaryan Elena Valerevna ${ }^{1}$ \\ 1 - Southern Federal University \\ 105 / 42 Bolshaya Sadovaya Str., 344006 Rostov-on-Don, Russia \\ 2 - Don State Technical University \\ Polytechnic Institute of Don State Technical University ${ }^{2}$ \\ 109A Petrovskaya Str., Taganrog, Rostov region, Russia
}

\section{Article Info}

Received May 12, 2019

\section{Keyword:}

Metal welding observation model regression shielding gas plasma-arc welding weld bead alloying prediction control.

\begin{abstract}
The usage relevance of linear observation models of welding processes is substantiated. A brief analytical review of scientific papers on using linear observation models for researching the processes of arc welding is introduced. An example of studies utilizing a linear observation model based on the results of experiments with alloying of a weld metal is given. The type of linear observation model - fractional replication - is determined. An experiment planning matrix and test results are given. After performing tests and processing the experimental data, mathematical models in the form of dependencies of the transfer of alloying elements into the weld metal were obtained. According to the results of the experiments, empirical models in the form of dependencies evaluating the percentages of manganese, silicon and carbon, transfer coefficients from the "wire-to-product" distance, the diameter of the welding nozzle and the filling wire feed rate were obtained. Since the degree of uncertainty of parameters during welding is high enough, the necessity of further modification of linear observation models using expert knowledge is justified. The mathematical specification of the linear observation model with parameters in the form of fuzzy intervals is given. An algorithm for identifying the parameters of a linear observation model in the form of fuzzy intervals has been developed.
\end{abstract}

\section{Corresponding Author:}

First Author,

1 - Southern Federal University

105 / 42 Bolshaya Sadovaya Str., 344006 Rostov-on-Don, Russia

Email: Ameerru88@gmail.com

\section{Introduction}

The problem of controlling the plasma welding arc is considered to be one of the complex process control problems. The reason for it is the lack of adequate mathematical models of combustion processes. However, studies in the field of synthesis of mathematical models of welding processes are underway. The direction of model development can be determined based on experimental studies of welding processes. The result is a 
model in the form of empirical dependencies, for example, current-voltage characteristics for different parameters of the welding process. A lot of papers following this direction, for example, works [1 - 3], have already been published. Another direction of model development is related to obtaining linear observation models (regression models). This type of model also establishes a connection between some parameters (factors) and a certain resulting parameter, for example, the welding efficiency criterion. The type of these models and the results of their application can be found in [4 - 7].

Also, welding control models can be used in the form of classic proportional-integral and proportional-integral-differential control algorithms [8]. Quite simple automatic control systems with one or two control loops can be created on the basis of these models [9 - 11].

Decision-making models created using expert knowledge [12-14] based on new information technologies are utilized to control the welding process. It should be noted that the degree of uncertainty of parameters during welding is quite large. Measuring equipment with a high degree of accuracy can be used, but this can only be applied for fixing welding results or running tests. Even if the experiment is conducted again with the same initial conditions it is nearly impossible to get the same results. Formalizing the uncertainty is possible using scientific assessment.

The development of any control system is carried out on the basis of a certain model; therefore, the development of new models or the modification of known models is an urgent task for the further development of effective welding process control systems.

\section{nalysis of the known welding process regression models.}

In this article a linear observation model for the plasma welding process with fuzzy parameters is developed. There is a known type of linear observation model which is also called a regression analysis model [15]. This model is defined as follows.

There are $n$ measurements $y_{1}, y_{2}, \ldots, y_{n}$ of the quantity $\mathrm{Y}$ that are determined as:

$$
\begin{gathered}
M\left\{y_{i}\right\}=x_{i 1} \beta_{1}+x_{i 2} \beta_{2}+\ldots+x_{i p} \beta_{p}, i=\overline{1, n}, \\
\operatorname{cov}\left\{y_{i} y_{j}\right\}= \begin{cases}\sigma^{2}, i=j, \\
0, i=j,\end{cases}
\end{gathered}
$$

where $\beta=\left\{\beta_{1}, \beta_{2}, \ldots, \beta_{n}\right\}$ is the vector of unknown parameters; $\sigma^{2}$ is the dispersion, $X=\left(x_{i j}\right), i=1,2, \ldots, n$, $j=1,2, \ldots, p$ is the known coefficients matrix of order $n \times p ; \operatorname{cov}\left\{y_{i}, y_{j}\right\}=M\left(y_{i}-M\left\{y_{i}\right\}\right)\left(y_{j}-M\left\{y_{j}\right\}\right)$ is the covariance between $y_{i}$ and $y_{j} ; M\{\ldots\}$ is a mathematical expectation operation.

The regression analysis model is a fundamental concept in mathematical statistics, since many statistical dependences of parameter changes are described by regression functions that are linear for unknown parameters and non-linear (in general) for independent variables called factors in experiment planning theory.

In this part we'll discuss some scientific articles that present the results of similar studies in relation to the processes of welding.

In [4], the use of a linear observation model as a heat transfer model in the form of an algebraic polynomial is shown. The output parameter of the model is the specified depth of the welded joint in gas metal arc welding. Input parameters are wire diameter, gas flow rate, welding speed, arc current, voltage. Experiments are conducted. The authors of [4] argue that the proposed model can be used to control the output parameter of the welding process while achieving high quality welding criteria. However, the authors mentioned the existence of a significant variation in the results found.

In [5], a description of experiments on welding of 08X18H9T stainless steel using an inert gas is given. A linear observation model was used to predict the results of welding and to study the effect of welding parameters. Parameters affecting the result of the welding process are current, arc voltage, speed, distance and the electrode angle. The quality of welding as an output parameter was determined by the shape and parameters of the weld. A mathematical model was developed, regression coefficients were found and the model was tested for adequacy based on the results of welding. Conclusions regarding the desired values of the parameters of the welding process control were made.

In [6], regression analysis models were researched for predicting the quality of the weld. The quality of the weld was determined depending on the welding speed, welding current and arc voltage. The study also took into account the surface temperatures of the welded product. The authors of [6] argue that empirical models can predict optimal welding parameters to achieve the required welding criteria. Models can be 
applied in automatic control systems and in an expert system to solve the problem of welding process optimization.

The results of work [7] are different. Not only the regression analysis model, but also its modification in the form of a fuzzy linear relationship between the output parameter and other parameters of the welding process are considered for predicting and controlling the parameters of the weld. In [7] it was shown that using a fuzzy regression model with such input parameters as wire diameter, arc voltage, welding speed and welding current, it is possible to perform the prediction of the output weld parameter. It is concluded that this approach can be extended to other types of models of the welding process.

Based on the results of the analysis it can be concluded that linear observation models (regression analysis models) are widely used to study welding processes and predict its results. Therefore, we'll consider an example of applying a linear observation model based on the results of experiments with alloying of a weld metal.

\section{The effect of plasma welding on the alloying of the weld metal.}

To obtain a weld metal with a given composition and properties we will experimentally determine the laws of oxidation of the molten metal during plasma welding in $\mathrm{CO} 2$ gas with a filler wire. The intensity of metal oxidation will be estimated by the change in the composition of the weld metal and the alloy transfer efficiency [16].

It is quite difficult to determine the effect of various parameters of the plasma welding process on the loss of alloying elements from oxidation analytically since there is a large number of factors affecting the transfer of alloying elements to the weld metal. The method of planning a multifactorial experiment is applied [15].

An analysis of a priori information allows us to determine many factors that affect the quality of the weld metal of plasma welding in $\mathrm{CO} 2$ with filler wire - the response function. These factors are the percentage of carbon $\left(\mathrm{y}_{1}\right)$, manganese $\left(\mathrm{y}_{2}\right)$ and silicon $\left(\mathrm{y}_{3}\right)$ in the weld metal, the transfer coefficients of carbon $\left(\mathrm{y}_{4}\right)$, manganese $\left(\mathrm{y}_{5}\right)$ and silicon $\left(\mathrm{y}_{6}\right)$ to the weld metal.

The utilization of the random balance method allows to identify factors that have the biggest effect and their interrelation. The list of factors and their variability intervals are shown in table 1.

Table 1

Multifactorial Experimental Conditions

\begin{tabular}{|l|c|c|c|c|c|}
\hline \multirow{2}{*}{ Variable factor } & \multicolumn{4}{|c|}{ The level of factors and the interval of variation } \\
\cline { 2 - 6 } & $\begin{array}{c}\text { Main level } \\
x_{i 0}\end{array}$ & $\begin{array}{c}\text { Variabili-ty } \\
\text { interval } \Delta x_{i}\end{array}$ & $\begin{array}{c}\text { Upper level } \\
x_{i}=+1\end{array}$ & $\begin{array}{c}\text { Lower level } \\
x_{i}=-1\end{array}$ & $\begin{array}{c}\text { Code } \\
\text { desig- } \\
\text { nation }\end{array}$ \\
\hline Welding current $I_{n l}, \mathrm{~A}$ & 190 & 50 & 240 & 140 & $x_{1}$ \\
\hline Welding speed $V_{c}, \mathrm{~m} / \mathrm{h}$ & 45 & 15 & 60 & 30 & $x_{2}$ \\
\hline $\begin{array}{l}\text { The distance between the nozzle } \\
\text { and the workpiece, } \mathrm{mm}\end{array}$ & 20 & 5 & 25 & 15 & $x_{3}$ \\
\hline $\begin{array}{l}\text { Diameter of the welding nozzle } \\
d_{c}, \mathrm{~mm}\end{array}$ & 7 & 1 & 8 & 6 & $x_{4}$ \\
\hline Plasma gas flow rate $g_{n \pi .2}, \mathrm{~g} / \mathrm{s}$ & 0,248 & 0,083 & 0,330 & 0,165 & $x_{5}$ \\
\hline
\end{tabular}

All factors are controlled, monitored and uncorrelated. Linear observation model is a fractional replica of the following type:

$$
y=b_{0}+\sum_{i=1}^{5} b_{i} x_{1}+b_{13} x_{1} x_{3}+b_{14} x_{1} x_{4},
$$

where $y$ is the response function; $x_{i}-$ influencing factors; $b_{i}$ - linear effects; $b_{13}, b_{14}-$ interaction effects.

Equation (3) is a regression model in the form of a fractional replica. This model allows to evaluate linear effects mixed with two-way interactions. The planning matrix and the average values of the optimization parameters are shown in Tables 2 and 3.

Table 2 
Planning Matrix and Results

\begin{tabular}{|c|c|c|c|c|c|c|c|c|c|}
\hline \multirow[t]{3}{*}{ Trial number } & \multicolumn{6}{|c|}{ Code } & \multicolumn{3}{|c|}{ Element concentration, $\%$} \\
\hline & \multirow[t]{2}{*}{$x_{0}$} & \multirow[t]{2}{*}{$x_{1}$} & \multirow[t]{2}{*}{$x_{2}$} & \multirow[t]{2}{*}{$x_{3}$} & \multirow[t]{2}{*}{$x_{4}$} & \multirow[t]{2}{*}{$x_{5}$} & C & $\mathrm{Mn}$ & $\mathrm{Si}$ \\
\hline & & & & & & & $y_{1}$ & $y_{2}$ & $y_{3}$ \\
\hline 1 & + & - & - & - & - & - & 0,10 & 0,39 & 0,14 \\
\hline 2 & + & + & + & - & - & - & 0,195 & 0,36 & 0,12 \\
\hline 3 & + & - & - & + & + & - & 0,12 & 0,45 & 0,20 \\
\hline 4 & + & + & - & + & - & + & 0,12 & 0,20 & 0,10 \\
\hline 5 & + & - & + & + & - & + & 0,16 & 0,48 & 0,19 \\
\hline 6 & + & + & - & - & + & + & 0,153 & 0,33 & 0,13 \\
\hline 7 & + & - & + & - & + & + & 0,13 & 0,72 & 0,26 \\
\hline 8 & + & + & + & + & + & - & 0,14 & 0,42 & 0,14 \\
\hline
\end{tabular}

Table 3

Planning Matrix and Results

\begin{tabular}{|c|c|c|c|c|c|c|c|c|c|}
\hline \multirow[t]{3}{*}{ Trial number } & \multicolumn{6}{|c|}{ Code } & \multicolumn{3}{|c|}{ Alloy Transfer Coefficients } \\
\hline & $x_{0}$ & $x_{1}$ & $x_{2}$ & $x_{3}$ & $x_{4}$ & $x_{5}$ & $\mu_{C}$ & $\mu_{M n}$ & $\mu_{S i}$ \\
\hline & & & & & & & $y_{1}$ & $y_{2}$ & $y_{3}$ \\
\hline 1 & + & - & - & - & - & - & 0,72 & 0,33 & 0,26 \\
\hline 2 & + & + & + & - & - & - & 1,38 & 0,36 & 0,26 \\
\hline 3 & + & - & - & + & + & - & 0,88 & 0,40 & 0,39 \\
\hline 4 & + & + & - & + & - & + & 0,83 & 0,22 & 0,23 \\
\hline 5 & + & - & + & + & - & + & 1,19 & 0,40 & 0,35 \\
\hline 6 & + & + & - & - & + & + & 1,07 & 0,35 & 0,30 \\
\hline 7 & + & - & + & - & + & + & 0,98 & 0,57 & 0,46 \\
\hline 8 & + & + & + & + & + & - & 1,01 & 0,39 & 0,29 \\
\hline
\end{tabular}

The experiments were performed in a random sequence, which eliminates the influence of systematic errors due to external conditions.

During the experiments, beads were welded on plates of VSt 3 steel with a thickness of $10 \mathrm{~mm}$ using the 1,6-Sv08G2S filler wire. Backhand welding was performed. Each experiment was repeated five times. The contents of alloying elements in the base metal are $0,16 \%$ of carbon; $0,43 \%$ of manganese; $0,23 \%$ of silicon. Contents in the filler wire are $0,11 \%$ of carbon; $1,95 \%$ of manganese; $0,84 \%$ of silicon.

The conditions of the experiments:

- the distance from the melting point of the filler wire to the nozzle exit section of the plasma torch is constant, therefore the length of the plasma arc determined the length of the path of the liquid metal droplets to the weld pool;

- melting of the wire occurred in the center of the plasma arc column.

The contents of elements in the welds were identified using chemical analysis. The edges of the analyzed metal sections of the welds were previously trimmed, ground and etched. After etching, edges for sampling were outlined with center punch. Sampling was carried out by drilling. Transverse templates were cut from the samples and were used to determine the cross-sectional area of the weld and the proportion of the main metal in it. The calculation of the transfer coefficients of alloying elements is made according to the formulas $[16,17]$ :

$$
\begin{aligned}
& \mu=C_{\amalg} / C_{h}, \\
& C_{H}=\theta C_{O^{+}}(1-\theta) C_{\Pi},
\end{aligned}
$$

where $\mu$ is the transfer coefficient of the corresponding element; $C_{U}$ is the concentration of the element in the weld metal (\%); $C_{И}$ is initial element concentration (\%); $\theta$ is the proportion of the base metal in the weld metal; $C_{O}$ and $C_{\Pi}$ are element concentration in the base metal and in the wire (\%) $[18,19]$.

Mathematical models in the form of the dependences of the transfer of alloying elements to the weld metal were obtained in the following form after performing the experiments and processing the experimental data: 
- carbon concentration in the weld metal model:

$$
y_{1}=0,14+0,012 x_{1}+0,0165 x_{2^{-}} 0,0173 x_{1} x_{3} ;
$$

- manganese concentration in weld metal model:

$$
y_{2}=0,419-0,091 \mathrm{x}_{1}+0,076 \mathrm{x}_{2}-0,031 \mathrm{x}_{3}+0,061 \mathrm{x}_{3} ;
$$

- silicon concentration in the weld metal model:

$$
y_{3}=0,16-0,0375 x_{1}+0,0175 x_{2}+0,0225 x_{4} ;
$$

- carbon transfer coefficient model:

$$
y_{4}=1,008+0,065 x_{1}+0,1325 x_{2}-0,1225 x_{1} x_{3} ;
$$

- manganese transfer coefficient model:

$$
y_{5}=0,378-0,0475 x_{1}+0,0525 x_{2}-0,025 x_{3}+0,05 x_{4} ;
$$

- silicon transfer coefficient model:

$$
y_{6}=0,3175-0,0475 x_{1}+0,0225 x_{2}+0,0425 x_{4} .
$$

An analysis of regression equations (6 - 11) showed that the plasma arc current $I_{n l}$, the welding speed $V_{c}$, the diameter of the welding nozzle $d_{c}$. have the biggest effect on the alloying of the weld metal and the transfer of elements to the weld metal. According to the results of the experiments, empirical models in the form of the dependences shown in Fig. 1 - 8 were obtained.

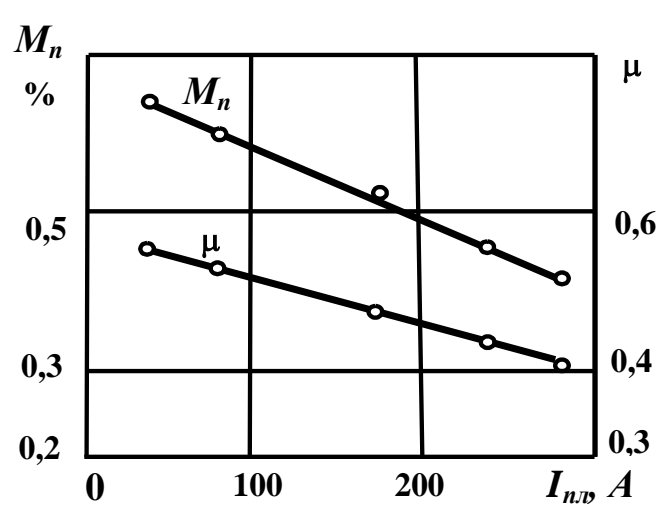

a)

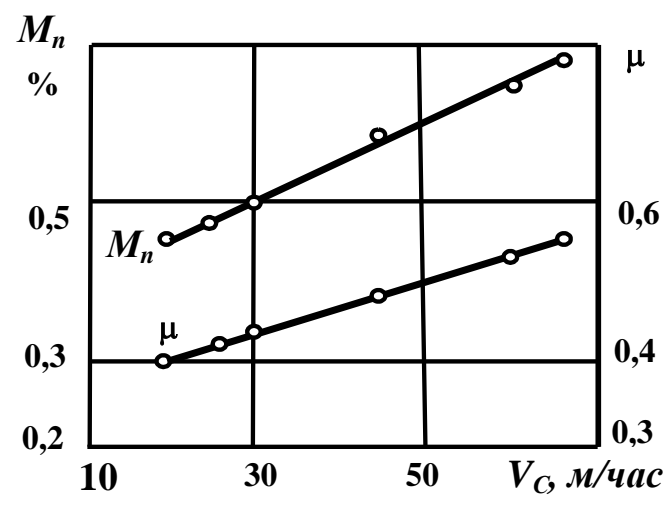

b)

Fig. 1. Dependence of manganese concentration and transfer coefficient of alloying elements on arc current (a) and welding speed (b): a) $d_{c}=8 \mathrm{~mm} ; g_{n л .2}=0,25 \mathrm{~g} / \mathrm{s}$; distance between nozzle and workpiece $L_{c-u}=15 \mathrm{~mm}$; $I_{n l}=160 \mathrm{~A}$; distance between wire and workpiece $L_{n p-u}=7 \mathrm{~mm} ; V_{c}=45 \mathrm{~m} / \mathrm{h} ;$ б) $d_{c}=8 \mathrm{~mm} ; g_{n л .2}=0,25 \mathrm{~g} / \mathrm{s} ; L_{c-u}=15$ $\mathrm{mm} ; L_{n p-u}=7 \mathrm{~mm}$ 


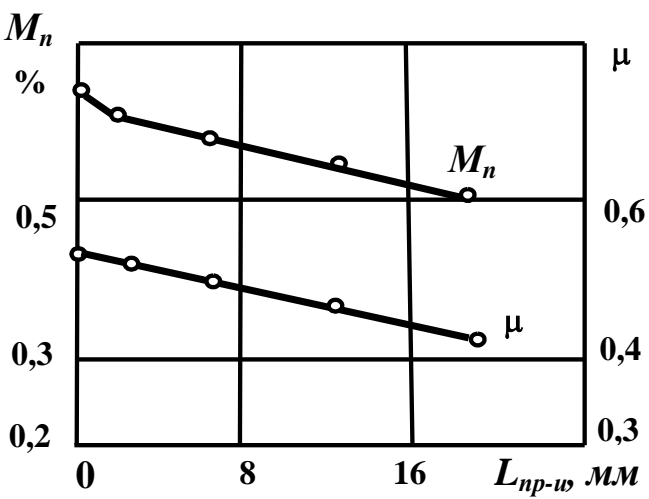

a)

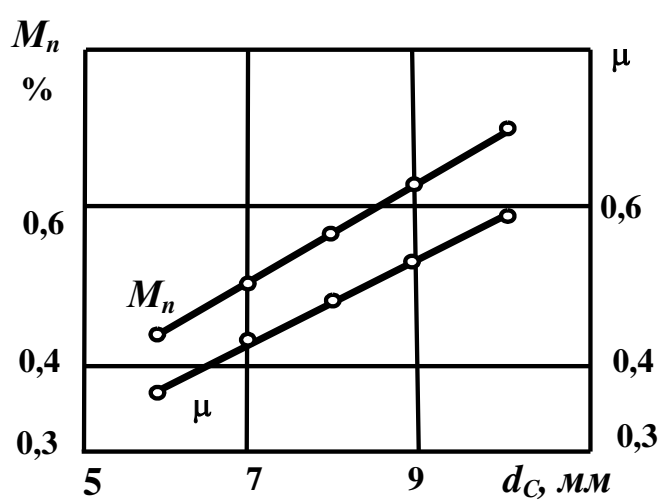

b)

Fig. 2. Dependence of manganese concentration and transfer coefficient on the wire to workpiece distance (a) and diameter of the welding nozzle (b):

a) $\left.I_{n l}=160 \mathrm{~A} ; d_{c}=8 \mathrm{~mm} ; g_{n л .2}=0,25 \mathrm{~g} / \mathrm{s} ; L_{c-u}=15 \mathrm{~mm} ; V_{c}=45 \mathrm{~m} / \mathrm{h} ; \mathrm{b}\right) I_{n l}=160 \mathrm{~A} ; g_{n л . .2}=0,25 \mathrm{~g} / \mathrm{s} ; L_{c-u}=15 \mathrm{~mm} ; L_{n p-}$ ${ }_{u}=7 \mathrm{~mm} ; V_{c}=45 \mathrm{~m} / \mathrm{h}$

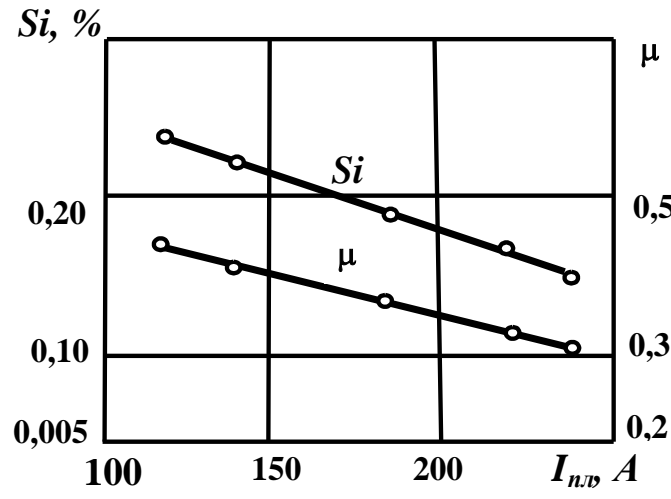

a)

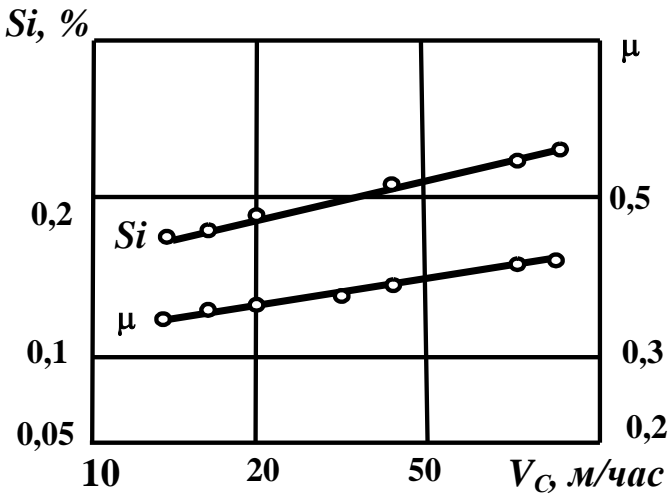

b)

Fig. 3. Dependence of silicon concentration and transfer coefficient on arc current (a) and welding speed (b):

a) $V_{c}=45 \mathrm{~m} / \mathrm{h}$; b) $I_{n л}=160 \mathrm{~A} ; d_{c}=8 \mathrm{~mm} ; g_{n л .2}=0,25 \mathrm{~g} / \mathrm{s}$;

$L_{c-u}=15 \mathrm{~mm} ; L_{n p-u}=7 \mathrm{~mm}$

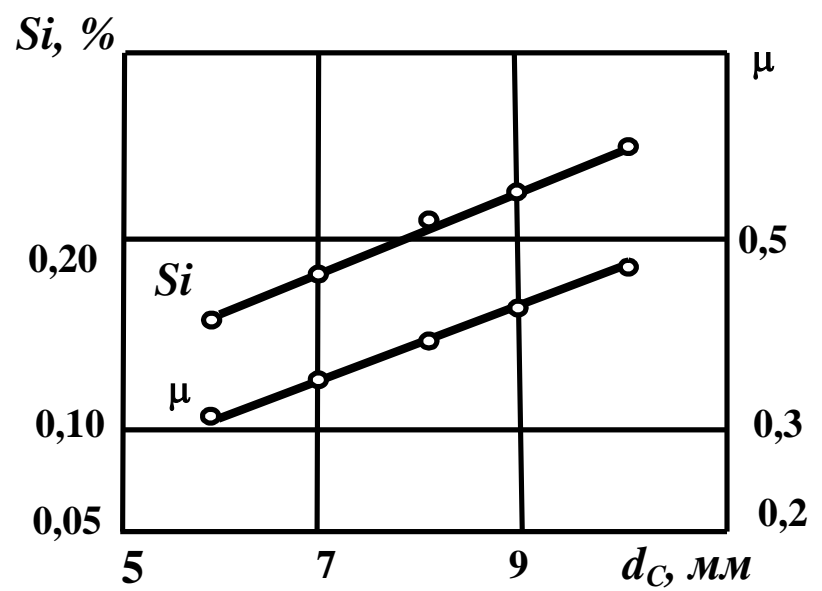

Fig. 4. Dependence of silicon concentration and transfer coefficient on the diameter of the welding nozzle:

$I_{n л}=160 \mathrm{~A} ; g_{n л .2}=0,25 \mathrm{~g} / \mathrm{s} ; L_{c-u}=15 \mathrm{~mm} ; L_{n p-u}=7 \mathrm{~mm} ; V_{c}=45 \mathrm{~m} / \mathrm{h}$ 

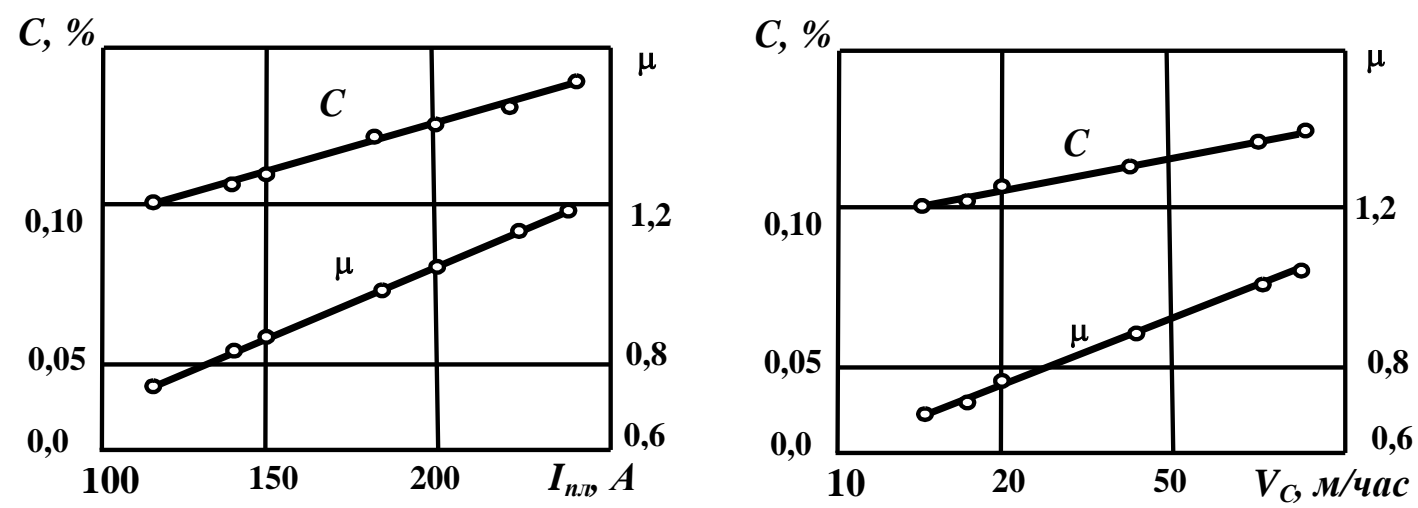

Fig. 5. Dependence of carbon concentration and transfer coefficient on arc current (a) and welding speed (b): a) $\left.d_{c}=8 \mathrm{~mm} ; g_{n л .2}=0,25 \mathrm{~g} / \mathrm{s} ; L_{c-u}=15 \mathrm{~mm} ; I_{n l}=160 \mathrm{~A} ; L_{n p-u}=7 \mathrm{~mm} ; V_{c}=45 \mathrm{~m} / \mathrm{h} ; \mathrm{b}\right) d_{c}=8 \mathrm{~mm} ; g_{n л .2}=0,25 \mathrm{~g} / \mathrm{s} ; L_{c-}$. ${ }_{u}=15 \mathrm{~mm} ; L_{n p-u}=7 \mathrm{~mm}$

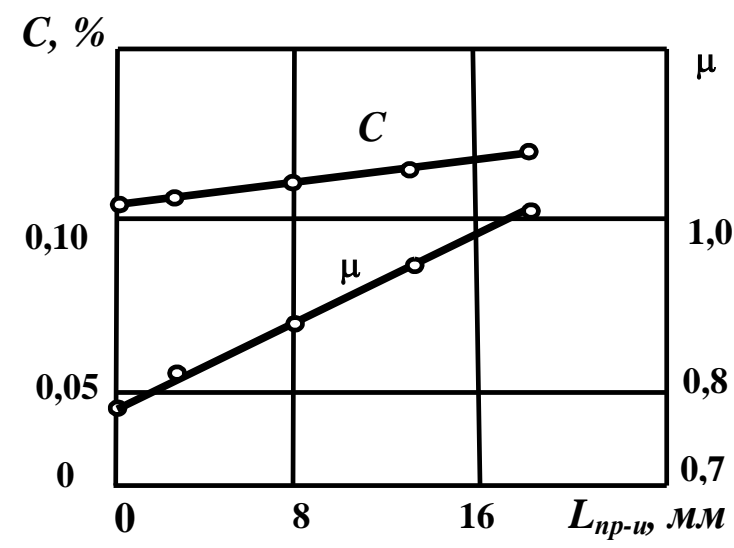

Fig. 6. Dependence of carbon concentration and transfer coefficient on the distance between the wire and the workpiece: $I_{n n}=160 \mathrm{~A} ; d_{c}=8 \mathrm{~mm} ; g_{n л .2}=0,25 \mathrm{~g} / \mathrm{s}$; $L_{c-u}=15 \mathrm{~mm} ; V_{c}=45 \mathrm{~m} / \mathrm{h}$
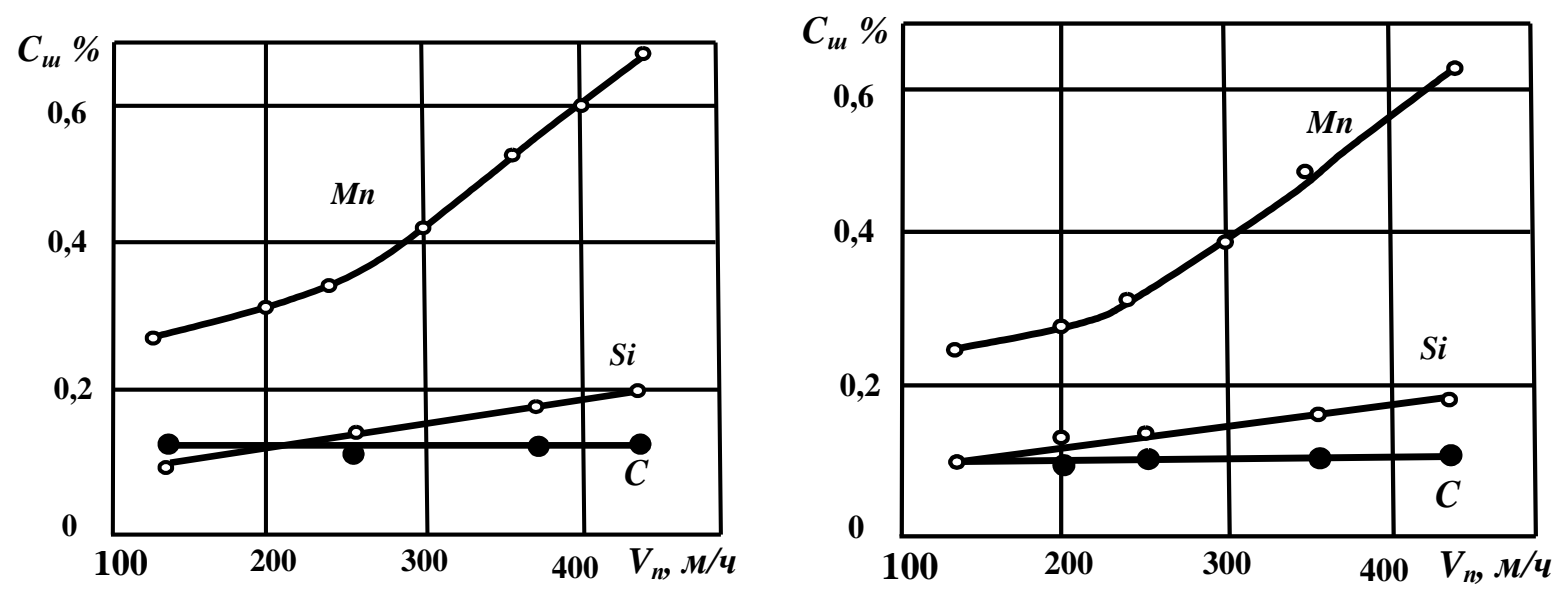

Fig. 7. Dependence of the concentration of elements in the weld metal on the filling wire feed rate: a) backhand; b) forehand; $I_{n n}=260 \mathrm{~A} ; d_{c}=8 \mathrm{~mm} ; g_{n л .2}=0,5 \mathrm{~g} / \mathrm{s} ; L_{c-u}=17 \mathrm{~mm} ; V_{c}=30 \mathrm{~m} / \mathrm{h}$ 


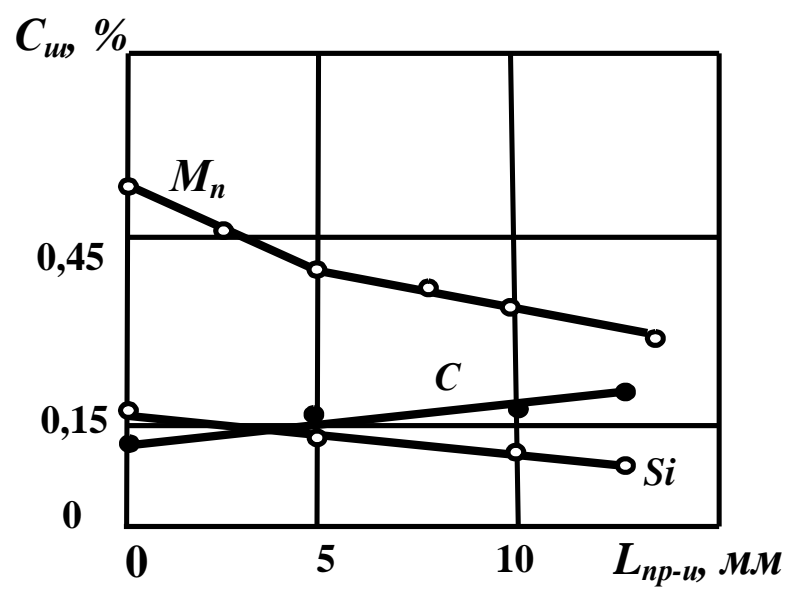

Fig. 8. Dependence of the concentration of elements in the weld metal on the wire to workpiece distance, forehand: $I_{n л}=260 \mathrm{~A} ; d_{c}=8 \mathrm{~mm} ; g_{n л .2}=0,5 \mathrm{~g} / \mathrm{s}$;

$L_{c-u}=17 \mathrm{~mm} ; V_{c}=30 \mathrm{~m} / \mathrm{h}$

Analysis of dependences in Fig. 1 - 6 shows that the convergence of experimental and calculated values of the percentage and transfer coefficients of alloying elements in the weld is within experimental error.

Fig. 7 and 8 show the dependences of the concentration of alloying elements in the weld metal on the feed rate of the filler wire obtained in single-factor experiments. Manganese losses grow with increase of arc current and wire-to-workpiece distance and with decrease of diameter of the welding nozzle and filling wire feed rate as well as during forehand welding (see Fig. 1- 6, 7b).

The growth in manganese losses with an increase of the arc current density, a decrease in the welding speed and an increase of the distance from the filler wire to the bath is related to intensification of oxidation processes at the drop and bath stages. The same results were also obtained when determining the effect of welding mode factors on the processes of alloying of a weld with silicon (see Fig. 3, 4).

While supplying the filler wire, which ensures the transfer of the filler metal behind the plasma arc column, the oxidation of the metal decreases (see Fig. $7 \mathrm{~b}$ and 8). The reason for it is that the transfer occurs in the low temperature zone.

If the filler wire is in a continuous contact with the bath during welding (see Fig. 8), there will be an increase in the concentration of alloying elements in the weld metal (see Fig. 2, 8). In this case, there is no transfer of liquid metal through the arc and the dwelling time of the drops in the high-temperature arc zone is reduced.

The concentration of alloying elements in the weld metal is influenced by the welding process scheme (see. Fig. 18 ). The concentration of alloying elements decreases when forehand welding with wire feed is performed (see Fig. 7b, 7) since there is an additional contact of liquid metal from the filler wire with a plasma arc in the weld pool.

The carbon concentration in the metal slightly increases with an increase of the arc current and a decrease of the welding speed.

The reliability of the results is reduced due to carbon and silicon possessing high affinity for oxygen and a significant amount of free oxygen in the high-temperature plasma arc. The concentration of these elements in the joints in all experiments was insignificant.

Thus, we can conclude that although performed experiments were successful, the problem of the accuracy of test results remains unsolved. To solve this problem, it is proposed to apply parameter interval estimation, i.e. their assignment in the form of fuzzy intervals [18]. When parameters are set in the form of fuzzy intervals their expert evaluations will simultaneously be both overestimated and underestimated. The carrier (base set) of the fuzzy interval is chosen so that the core contains the most plausible values and the parameter in question is guaranteed to be within the required limits. Linear observation models can be modified when parameters in the form of fuzzy intervals are applied. 


\section{Linear observation model with fuzzy parameters.}

In the modified linear observation model with fuzzy parameters each $j$-th input variable will be considered as a fuzzy variable $\tilde{x}_{j}$, given in the base set $X J$ in the form of a fuzzy interval. For plasma welding process $\tilde{X}=\left(\tilde{x}_{1}, \tilde{x}_{2}, \ldots, \tilde{x}_{m}\right)$ is a fuzzy point in the state space of input variables $\{X, \mathbf{M}\}$, where $\mathbf{M}$ is an algebra defined over fuzzy intervals. $\{B, \mathbf{N}\}$ is the space of state variables of the plasma welding process. The state of the plasma welding process is considered as a fuzzy point. $\widetilde{B}=\left(\tilde{b}_{1}, \tilde{b}_{2}, \ldots, \tilde{b}_{r}\right)$. Then $\mathbf{N}$ is an algebra defined over fuzzy intervals. For each component $\tilde{b}_{j}$ of vector $\widetilde{B}$ a mathematical model that determines the dependence of the component $\tilde{b}_{j}$ on the components of the vector $\tilde{X}$ is set in the form of a regression equation with fuzzy parameters

$$
\tilde{b}_{j}=\tilde{f}_{j}\left(\tilde{x}_{1}, \tilde{x}_{2}, \ldots, \tilde{x}_{m}\right), \quad j=\overline{1, r} .
$$

If fuzzy variables $\tilde{x}_{j}$ are considered as elements of the plasma welding process control, then the mathematical model (12) is an extension of the well-known linear observation model [15] that allows to make prediction of the state and the result of plasma welding depending on the existing fuzzy input parameters $\tilde{X}=\left(\tilde{x}_{1}, \tilde{x}_{2}, \ldots, \tilde{x}_{m}\right)$.

Defining parameters in the form of fuzzy intervals of linear observation model. According to the experiments on plasma welding, $n$ measurements $b_{1}^{k}, b_{2}^{k}, \ldots, b_{n}^{k}$ of the random component $b_{k}, k=\overline{1, r}$ of the vector $B$ can be obtained. For each measurement result a mathematical model with fuzzy intervals can be determined in the following form:

$$
\begin{aligned}
\left.M_{\{} \tilde{b}_{i}^{k}\right\} \cong \tilde{x}_{i 1}^{k} \tilde{\alpha}_{1}^{k} \tilde{+}_{i 2}^{k} \tilde{\alpha}_{2}^{k} \tilde{+} \ldots \tilde{+}_{i m}^{k} \tilde{\alpha}_{m}^{k}, \quad i \overline{1, n}, \\
\operatorname{cov}\left\{\tilde{b}_{i}^{k} \tilde{b}_{j}^{k}\right\} \cong \begin{cases}\sigma^{2}, i=j, \\
0, i \neq j,\end{cases}
\end{aligned}
$$

where $\tilde{\alpha}^{k}=\tilde{\alpha}_{1}^{k}, \tilde{\alpha}_{2}^{k}, \ldots, \tilde{\alpha}_{m}^{k} \quad$ - unknown fuzzy parameters vector; $\sigma^{2}$ - dispersion, $X^{k}=\left(\tilde{x}_{i j}^{k}\right), i=\overline{1, n}, j-\overline{1, m}, k=\overline{1, r}-$ known fuzzy coefficients matrix of order $n \times p$; $\operatorname{cov}\left\{\tilde{b}_{i}^{k} \tilde{b}_{j}^{k}\right\} \cong M\left(\tilde{b}_{i}^{k}-M\left\{\tilde{b}_{i}^{k}\right\}\right)\left(\tilde{b}_{j}^{k}-M\left\{\tilde{b}_{j}^{k}\right\}\right)$ - covariance between $\tilde{b}_{i}^{k}$ and $\tilde{b}_{j}^{k}, M\{$.$\} -$ mathematical expectation operation, $\cong$ - fuzzy equality sign, $\tilde{+}$ - fuzzy sum operation.

Model (13) determines the fuzzy dependence of observation results $\left\{b_{i}\right\}$ on fuzzy values $\left\{\tilde{x}_{i j}\right\}$, and condition (14) determines the requirement that the random variables are uncorrelated $\left\{b_{i}\right\}$ and dispersions are equal $\sigma^{2}$ for measurements $b_{i}, i=\overline{1, n}$.

Implementation of the experiment with fuzzy intervals. The purpose of the experiment is to control the output parameters of welding via prediction and decision making. The conditions for planning an experiment with a model are:

- selection of the minimum number of experiments;

- the possibility of selecting regression model variables that determine the state of the plasma welding process according to specified rules;

- algorithmization of the experiment;

- the possibility of obtaining valid decisions in the form of logical decision rules after processing each series of experiments. 
While planning an extreme experiment to control the plasma welding process it is necessary to determine the parameter that needs to be optimized, for example, find the maximum value of the integral criterion that determines the quality level of the weld.

The state and result of the plasma welding process can be affected by many factors, from which it is worthwhile to select the most significant ones, i.e. apply methods of eliminating non-essential factors [19,20]. However, the experimental error may increase if any factor that may later prove to be significant is ignored, therefore, it is necessary to involve experts on the plasma welding processes.

The formalization of the experiment is as follows. Suppose there are statistical data on the results of plasma welding. The experiment involves the occurrence of $n$ measurements for the research of the $k$-th component $\widetilde{B}^{k}=\left\{\tilde{b}_{1}^{k}, \tilde{b}_{2}^{k}, \ldots, \tilde{b}_{n}^{k}\right\}, k=\overline{1, r}$ of fuzzy states vector $\widetilde{B}$ of welding process in fuzzy points of the multidimensional space of input variables $\{X, \mathbf{M}\}$. The correspondence between the elements of the set $\tilde{B}$ and a set $X$, the graph of which consists of $n$ twos can be obtained. The first element of each one of them is the result of measurement, and the second element is a fuzzy point in space $\{X, \mathbf{M}\}$

$$
\left\{\left(\tilde{b}^{k 1}, \tilde{X}^{k 1}\right),\left(\tilde{b}^{k 2}, \tilde{X}^{k 2}\right), \ldots,\left(\tilde{b}^{k n}, \tilde{X}^{k n}\right)\right\} \text {. }
$$

Set of fuzzy points $\tilde{X}^{k}=\left\{\tilde{X}^{k 1}, \tilde{X}^{k 2}, \ldots, \tilde{X}^{k u}\right\}$ is a plan for performing a plasma welding experiment.

The experimental design matrix for the study of the $k$-th component $\widetilde{B}^{k}$ of the state vector $\tilde{B}$ of the plasma welding process is as follows:

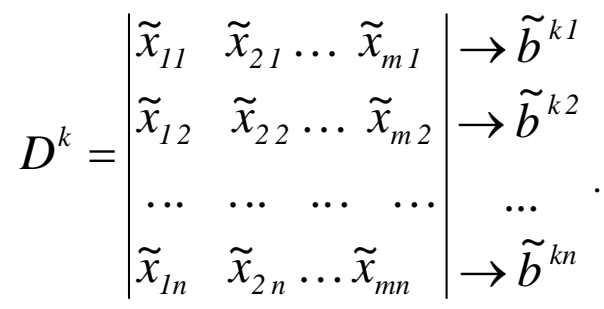

For each $u$-th measurement of fuzzy parameters, the mathematical expectation is determined $\mathbf{M}\left\{\tilde{\mathrm{b}}^{\mathrm{u}} \widetilde{\mathrm{x}}_{1 \mathrm{u}}^{\mathrm{k}}, \tilde{\mathrm{x}}_{2 \mathrm{u}}^{\mathrm{k}}, \ldots, \tilde{\mathrm{x}}_{\mathrm{mu}}^{\mathrm{k}}\right\}=\sum_{\mathrm{j}=1}^{\mathrm{m}} \mathrm{f}_{\mathrm{j}}\left(\tilde{\mathrm{x}}_{1 \mathrm{u}}^{\mathrm{k}}, \tilde{\mathrm{x}}_{2 \mathrm{u}}^{\mathrm{k}}, \ldots, \tilde{\mathrm{x}}_{\mathrm{mu}}^{\mathrm{k}}\right) \tilde{\alpha}_{m}^{k}$ in vector form

$$
M\left\{\tilde{B}^{k}\right\}=\tilde{X}^{k} \tilde{A}^{k},
$$

where $\tilde{X}^{k}=\left\{\tilde{x}_{i u}^{k}\right\}$ is a matrix of known coefficients in the form of fuzzy intervals that will be referred to as a matrix of independent fuzzy variables or a matrix of fuzzy planning.

A welding experiment in which the levels of each input fuzzy variable are combined with all levels of other input fuzzy variables is called a full factorial fuzzy experiment (FFFE) $[20,21,22]$.

By analogy with the known experiment planning method with a clear assignment of factors, FFFE requires defining the conditions for a fuzzy unambiguous definition of unknown coefficients estimations in the form of fuzzy intervals $\tilde{\hat{\alpha}}^{k}=\left(\widetilde{\hat{\alpha}}_{1}, \widetilde{\hat{\alpha}}_{2}, \ldots, \tilde{\hat{\alpha}}_{m}\right)$ in the equation (16):

- the fuzzy sum of the elements of the column vector of the matrix $\tilde{X}^{k}$ is fuzzy equal to zero:

$$
\sum_{i=1}^{n} \tilde{x}_{i u}^{k} \cong 0, \quad i=\overline{1, m}, \quad u=\overline{1, n}, k=\overline{1, r} ;
$$

- the sum of squares of fuzzy elements of each column $X_{i}^{k}$ of the matrix $\tilde{X}^{k}$ is fuzzy equal to the number of experiments (normalization requirement), i.e.

$$
\sum_{i=1}^{n} \tilde{x}_{i u}^{k 2}=\left\|X_{i}^{k}\right\|^{2}=n
$$

- the sum of the products of any two column vectors of the matrix $X_{i}^{k}$ is fuzzy equal to zero (orthogonality property of the design matrix): 


$$
\sum_{\mathrm{u}=1}^{\mathrm{n}} \stackrel{;}{\tilde{\mathrm{x}}_{\mathrm{lu}}^{\mathrm{k}}} \tilde{\mathrm{x}}_{\mathrm{su}}^{\mathrm{k}}=\left(\mathrm{X}_{1}^{\mathrm{k}}\right)^{\mathrm{T}} \mathrm{X}_{\mathrm{s}}^{\mathrm{k}}=0, \quad 1, \mathrm{~s}=\overline{0, \mathrm{n}}, \quad \mathrm{l}=\mathrm{s}, \mathrm{k}=\overline{1, \mathrm{r}}
$$

- fuzzy rotatability, i.e. fuzzy points in the plan matrix $\tilde{X}^{k}$ are selected so that the accuracy of prediction of the values of the fuzzy component of the vector $B$ (optimization parameter) is the same at fuzzy equal distances from the fuzzy center of the experiment and does not depend on the direction.

Defining fuzzy parameters of the regression analysis model. Suppose the model for evaluating the $k$ th, $k=\overline{1, r}$ fuzzy component $\widetilde{B}^{k}$ of state vector $\widetilde{B}$ of the plasma welding process is determined by the FFFE equation

$$
\begin{gathered}
\tilde{b}^{k} \cong \tilde{a}_{0}^{k} \tilde{+} \sum_{l<i<m} \tilde{a}_{i}^{k} \tilde{x}_{i}^{k} \tilde{+} \sum_{l<i<j<m} \tilde{a}_{i j}^{k} \tilde{x}_{i}^{k} \tilde{x}_{j}^{k} \tilde{+} \\
+\sum_{1<i<j<l<m} \tilde{a}_{i j l}^{k} \tilde{x}_{i}^{k} \tilde{x}_{j}^{k} \tilde{x}_{l}^{k} \tilde{+} \ldots \tilde{+} \tilde{a}_{123 \ldots m}^{k} \tilde{x}_{1}^{k} \tilde{x}_{2}^{k} \ldots \tilde{x}_{m}^{k},
\end{gathered}
$$

with coefficients presented in the form of fuzzy intervals.

Parameter $\tilde{x}_{i}^{k}, \quad i=\overline{1, m}$ of the fuzzy equation (20) is defined as the fuzzy linear effect of the input variable $\tilde{x}_{i}^{k}$, coefficient $\tilde{a}_{i_{1} i_{2} \ldots i_{p}}^{k}$ is an interaction effect of a fuzzy product of factors $\tilde{x}_{i_{1}}^{k} \tilde{x}_{i_{2}}^{k} \ldots \tilde{x}_{i_{p}}^{k}$, a fuzzy product $\tilde{x}_{i_{1}}^{k} \tilde{x}_{i_{2}}^{k} \ldots \tilde{x}_{i_{p}}^{k}, i<i_{1}<i_{2}<\ldots<i_{p}<m$ is defined as fuzzy interaction of $(p-1)$-th order of factors $\tilde{x}_{i_{1}}^{k} \tilde{x}_{i_{2}}^{k} \ldots \tilde{x}_{i_{p}}^{k}$ given in the form of fuzzy intervals.

The model of the fuzzy component $\widetilde{B}^{k}$ of the plasma welding process state vector $\tilde{B}$ is defined. As an example, FFFE with three independent variables $\tilde{x}_{i}^{k}, \quad i=\overline{1,3}$ consists of $2^{4}=16$ experiments, and the $2^{3}$ FFFE matrix of coded independent variables for the response function (20) is as follows:

$$
X=\left|\begin{array}{rrrrrrrr}
1 & -1 & -1 & -1 & 1 & 1 & 1 & -1 \\
1 & 1 & -1 & -1 & -1 & -1 & 1 & 1 \\
1 & -1 & 1 & -1 & -1 & 1 & -1 & 1 \\
1 & 1 & 1 & -1 & 1 & -1 & -1 & -1 \\
1 & -1 & -1 & 1 & 1 & -1 & -1 & 1 \\
1 & 1 & -1 & 1 & -1 & 1 & -1 & -1 \\
1 & -1 & 1 & 1 & -1 & -1 & 1 & -1 \\
1 & 1 & 1 & 1 & 1 & 1 & 1 & 1
\end{array}\right| .
$$

Identification of fuzzy coefficients $\hat{\tilde{a}}^{k}=\left(\hat{\tilde{a}}_{0}^{k}, \hat{\tilde{a}}_{1}^{k}, \ldots, \hat{\tilde{a}}_{n}^{k}\right)$ is done by using the criterion for minimizing the deviations of fuzzy parameter values $\tilde{b}^{k}$ from its measured values $\hat{\tilde{b}}^{k}$, so:

$$
\tilde{Q} \simeq \bigcup_{i=1}^{n}\left(\tilde{b}^{k}|-| \hat{\tilde{b}}^{k}\right)^{2} \rightarrow \min ,
$$

where $|-|$ - limited difference of fuzzy numbers determined by the formula [23, 24]:

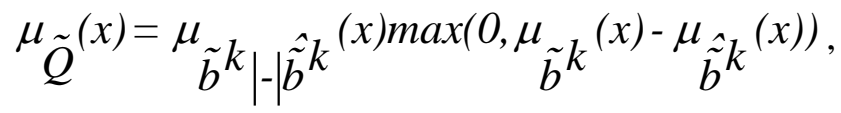

where $x$ - the variable of the base set, in which the $k$-th component of the vector $B$ of the design parameters of the plasma welding process is specified.

Thus, in the process of estimation of unknown fuzzy coefficients $\tilde{a}^{k}=\left(\tilde{a}_{0}^{k}, \tilde{a}_{1}^{k}, \ldots, \tilde{a}_{n}^{k}\right)$ a model (20) is reduced to the form of the equation: 


$$
\tilde{b}^{k} \cong \tilde{a}_{0}^{k} \tilde{+} \tilde{a}_{1}^{k} \tilde{x}_{1}^{k} \tilde{+} \tilde{a}_{2}^{k} \tilde{x}_{2}^{k} \tilde{+} \ldots \tilde{+} \tilde{a}_{m}^{k} \tilde{x}_{m}^{k} .
$$

Then fuzzy coefficient estimation $\tilde{a}^{k}=\left(\tilde{a}_{0}^{k}, \tilde{a}_{1}^{k}, \ldots, \tilde{a}_{n}^{k}\right)$ in the equation (24) comes down to the determination of fuzzy coefficients $\hat{\tilde{a}}^{k}=\left(\hat{\tilde{a}}_{0}^{k}, \hat{\tilde{a}}_{1}^{k}, \ldots, \hat{\tilde{a}}_{n}^{k}\right)$ that satisfy the condition (23)[25].

The model identification algorithm with parameters in the form of fuzzy intervals is shown in Fig. 9.

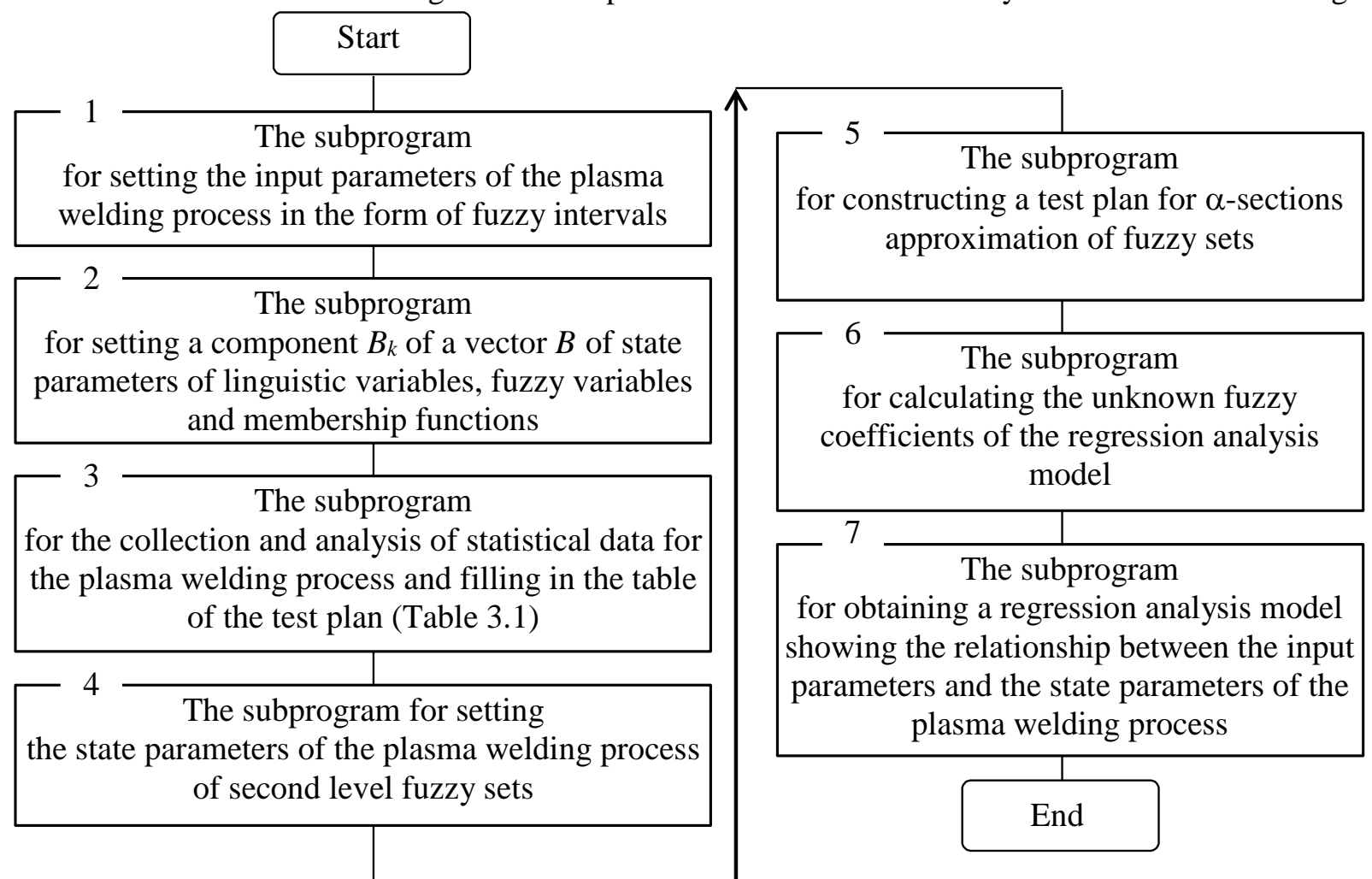

Fig. 9. The algorithm for identifying parameters in the form of fuzzy intervals

\section{Conclusion.}

The relevance of the usage of linear observations models of welding processes and the need for their further modification are substantiated. Modification of linear observation models is related to specifying model parameters in the form of fuzzy intervals. It allows to obtain reliable results from the simulation of the welding process by applying the expert knowledge. The mathematical assignment of the linear observation model is performed when parameters are specified in the form of fuzzy intervals. An algorithm for identifying the parameters of a linear observation model in the form of fuzzy intervals has been developed. This algorithm will be useful for further modeling software development.

The usage of a linear observation model for studying the effect of plasma welding on the alloying of the weld metal is shown. An experiment planning matrix has been composed. Experimental results were obtained and processed, which allowed us to obtain empirical dependences of the manganese concentration and the transfer coefficient of alloying elements to the welding seam on the arc current and welding speed, the dependence of the manganese concentration and transfer coefficient on the wire-to-workpiece distance and the diameter of the welding nozzle as well as other empirical dependencies that allowed to make conclusions regarding the desired parameters of the welding process to obtain high-quality weld.

\section{Acknowledgments}

The work was supported by grant The Russian fund of basic researches, The project №19-07-00936. 


\section{References}

[1] Wu CS, Wang L, Ren WJ, Zhang XY. Plasma arc welding: Process, sensing, control and modeling. Journal of manufacturing processes. 2014 Jan 1;16(1):74-85.

[2] Moore KL, Abdelrahman MA, Naidu DS. Gas metal arc welding control-II. Control strategy. Nonlinear Analysis: Theory, Methods \& Applications. 1999 Jan 1;35(1):85-93.

[3] Zhou K, Cai L. A nonlinear current control method for resistance spot welding. IEEE/ASME Transactions on Mechatronics. 2013 Mar 19;19(2):559-69.

[4] Kim IS, Basu A, Siores E. Mathematical models for control of weld bead penetration in the GMAW process. The International Journal of Advanced Manufacturing Technology. 1996 Nov 1;12(6):393401.

[5] Khanna P, Maheshwari S. Development of mathematical models for prediction and control of weld bead dimensions in MIG welding of stainless steel 409M. Materials Today: Proceedings. 2018 Jan $1 ; 5(2): 4475-88$.

[6] Son JS, Lee JP, Park MH, Jin BJ, Yun TJ, Kim IS. A study on on-line mathematical model to control of bead width for arc welding process. Procedia engineering. 2017 Jan 1;174:68-73.

[7] Xue Y, Kim IS, Son JS, Park CE, Kim HH, Sung BS, Kim IJ, Kim HJ, Kang BY. Fuzzy regression method for prediction and control the bead width in the robotic arc-welding process. Journal of Materials Processing Technology. 2005 May 15;164:1134-9.

[8] Besekersky VA, Popov EP. Theory of systems of automatic control. M: Nauka. 1975.

[9] Subbanna SR. Analysis of Proportional Integral and Optimized Proportional Integral Controllers for Resistance Spot Welding System (RSWS)-A Performance Perspective. InIOP Conference Series: Materials Science and Engineering 2017 Aug (Vol. 225, No. 1, p. 012175). IOP Publishing.

[10] Chu WH, Tung PC. Development of an automatic arc welding system using a sliding mode control. International Journal of Machine Tools and Manufacture. 2005 Jun 1;45(7-8):933-9.

[11] Huang YW, Tung PC, Wu CY. Tuning PID control of an automatic arc welding system using a SMAW process. The International Journal of Advanced Manufacturing Technology. 2007 Aug 1;34(1-2):5661.

[12] Fonseca CM, Fleming PJ. An overview of evolutionary algorithms in multiobjective optimization. Evolutionary computation. 1995 Mar;3(1):1-6.

[13] Adekunle AA, Ogbeide SO, Olorunfemi BJ, Adekunle OR. Development of computer aided design software for expert systems in welding. Journal of Emerging Trends in Engineering and Applied Sciences. 2016 Jun 1;7(3):95-102.

[14] Chen C, Lv N, Chen S. Data-Driven Welding Expert System Structure Based on Internet of Things. InTransactions on Intelligent Welding Manufacturing 2018 (pp. 45-60). Springer, Singapore.

[15] Almasani SA, Finaev VI, Qaid WA, Tychinsky AV. The Decision-making Model for the Stock Market under Uncertainty. International Journal of Electrical \& Computer Engineering (2088-8708). 2017 Oct $1 ; 7(5)$.

[16] Antonini JM. Health effects of welding. Critical reviews in toxicology. 2003 Jan 1;33(1):61-103.

[17] Deyev GF. Surface phenomena in fusion welding processes. cRc Press; 2005 Dec 19.

[18] Dubois D, Prade H, editors. Fundamentals of fuzzy sets. Springer Science \& Business Media; 2012 Dec 6.

[19] Elangovan M, Thenarasu M. Design of flexible spot welding cell for Body-In-White (BIW) assembly. Periodicals of Engineering and Natural Sciences. 2018 Oct 19;6(2):23-38. 
[20] Durakovic B. Design for Additive Manufacturing: Benefits, Trends and Challenges. Periodicals of Engineering and Natural Sciences. 2018 Dec 11;6(2):179-91.

[21] Mizumoto M, Tanaka K. Fuzzy sets and their operations. Information and Control. 1981 Jan 1;48(1):3048.

[22] Ulubeyli S, Kazaz A, Arslan V. A structured selection process for small and medium enterprises in construction industry: case of international projects. Periodicals of engineering and natural sciences. 2017 Oct $18 ; 5(3)$..

[23] Nzioka AM. Kinetic Study of the Thermal Decomposition for Mixed Municipal Solid Waste Using Thermogravimetric Analysis. Periodicals of Engineering and Natural Sciences. 2017 Oct 18;5(3)..

[24] Kucuk SD, Gerengi H, Guner Y. The Effect of Tinuvin Derivatives as an Ultraviolet (UV) Stabilizer on EPDM Rubber. Periodicals of Engineering and Natural Sciences. 2018 Mar 16;6(1):52-62.

[25] Musa KM, Shattnan AT, Saleh AH. Manufacturing Enamel Resin Using Furancarboxalehyde-3 Compound. Journal of Computational and Theoretical Nanoscience. 2019 Jan 1;16(1):130-3.

[26] S. Rawan and A. Manal, "Real time data analysis and visualization for the breast cancer disease," Period. Eng. Nat. Sci., vol. 7, no. 1, pp. 395-407, 2019.

[27] D. Y. Mahmood, A. G. Ismaeel, and A. H. Taqi, "Mining Method for Cancer and Pre-Cancer Detection Caused by Mutant Codon 248 in TP53," Period. Eng. Nat. Sci., vol. 7, no. 2, pp. 522-533, 2019.

[28] Z. YILMAZ, M. OKSAR, and F. BASCIFTCI, "Multi-Objective Artificial Bee Colony Algorithm to Estimate Transformer Equivalent Circuit Parameters," Period. Eng. Nat. Sci., vol. 5, no. 3, pp. 271$277,2017$.

[29] T. TUNCER, "SCSO: A novel sine-cosine based swarm optimization algorithm for numerical function optimization," Period. Eng. Nat. Sci., vol. 6, no. 2, pp. 1-9, 2018. 